\title{
Engineering application of ecological lake purification tailwater from sewage plant in vein industrial park
}

\author{
Lintang $\mathrm{Yu}^{1 *}$, Zhongya Tang ${ }^{2}$, Li Feng ${ }^{3}$, Junjie Ji ${ }^{1}$ \\ ${ }^{1}$ School of Environmental Engineering and Science, Yangzhou University, Yangzhou, Jiangsu 225127, China; \\ ${ }^{2}$ Yangzhou Water Supply and Drainage Management Office, Yangzhou, Jiangsu 225000, China; \\ ${ }^{3}$ Jiangsu Meijing Times Environmental Protection Technology Co. ,Ltd.Yangzhou, Jiangsu 225000, China.
}

\begin{abstract}
As the raising of environmental protection requirements, the outlet water (tailwater) quality standards of many sewage treatment plants need to be further improved. This paper mainly introduces the advanced treatment of tailwater from sewage treatment plant of vein industrial park by artificial ecological lake. The designed processing amount of this project was $1300 \mathrm{~m}^{3} / \mathrm{d}$, the inlet water COD was $30 \mathrm{mg} / \mathrm{L}$, the ammonia nitrogen content was $1.5 \mathrm{mg} / \mathrm{L}$, and the outlet water main index reached the surface water environment quality standard (GB3838-2002) III class water quality standard, which had improved the outlet water (tailwater) quality of sewage treatment plants and improved the regional water environment quality. By constructing an artificial landscape lake, the resource utilization of tailwater can be realized.
\end{abstract}

\section{Introduction}

With the rapid development of China's economy, the output of domestic sewage and industrial wastewater has increased significantly, seriously polluting water bodies. The construction and operation of sewage treatment plants at all levels has reduced some of the pollutants entering the water body, but the outlet water (tailwater) of these sewage treatment plants still contains a large number of pollutants, which is still an important source of pollution for the receiving water body ${ }^{[1]}$. In addition, the tailwater also contains some toxic and harmful substances that are difficult to be absorbed and degraded by organisms. Direct discharge may not only lead to eutrophication of the water body, but also cause ecological toxicity and endanger human health ${ }^{[2]}$. Therefore, it is particularly necessary to carry out advanced treatment of the outlet water from the sewage treatment plant ${ }^{[3]}$. Although the three-stage treatment process (biological or chemical) that is conventionally used at present can remove nitrogen and phosphorus from sewage, it has the problems of large investment, high operating costs, and unsatisfactory purification effects $^{[4]}$. The ecological engineering technologies (artificial wetlands, biological floating islands, etc.) can meet the technical requirements of advanced treatment, which have the advantages of low investment, maintenance and operating costs, simple management, good treatment effect, small secondary pollution, and strong impact resistance ${ }^{[5,6]}$.

Utilizing these advantages of artificial wetlands and the environmental landscaping value of wetland plants, the fully combination of sewage treatment and the creation of ecological landscapes has good economic, ecological and social benefits ${ }^{[7]}$. Before being discharged into the river, the outlet water (tailwater) of the sewage treatment plant in a vein industrial park was processed by an artificial ecological lake, which combined the landscaping value of wetland plants with garden landscape art, adding an artificial ecological wetland landscape to the industrial park. Citizens and foreign tourists provided a leisure place that integrates life and rest, ecological popularization and education, which greatly reduced the pollutants emission, while making full use of water resources and beautifying the environment.

\section{Project Overview}

The vein industrial park is to realize the integrated planning, stage construction and centralized management of waste treatment projects such as kitchen waste treatment, household waste classification and recovery treatment (sanitary landfill, incineration, etc.), building decoration waste treatment, household waste classification and recovery treatment, electronic and electrical waste classification and recovery treatment, sludge treatment, etc. The vein industrial park has a sewage treatment plant with a processing amount of $1,300 \mathrm{~m}^{3} / \mathrm{d}$.

This project is a systematic project for the ecological treatment of the tailwater of the sewage treatment plant in the vein industrial park, which will further reduce the impact of the tailwater of the sewage treatment plant on the surrounding river water quality. It is proposed to improve the water quality and restore the ecology of the effluent from the sewage plant through the construction of ecological artificial lake and the filtration system of

\footnotetext{
*Corresponding author: yzylt@163.com
} 
ecological wetland, and the natural ways such as precipitation, filtration, adsorption and purification of aquatic plant community. This project covers an area of about 45,000 square meters and is located in the northeast corner of the park. The river area is about 20,000 square meters. The tailwater discharged from the sewage treatment plant in the park is connected to the system from the southwest corner of the ecological lake and discharged into the river from the southeast corner of the ecological lake. Through the technological measures of the ecological lake system, the water quality can be improved from surface water Class IV to Class III.

\section{Process flow and water quality parameters}

\subsection{Design scale}

According to relevant data, the discharge amount of the sewage treatment plant in the industrial park is 1300 $\mathrm{m}^{3} / \mathrm{d}$, and this project treats the tailwater discharged from this sewage treatment plant in the industrial park, so this project is designed to handle $1300 \mathrm{~m}^{3} / \mathrm{d}$.

\subsection{Designed of inlet and outlet water quality}

Table 1 shows the water quality design indicators for the artificial lake treatment system.

Table 1. Designed inlet and outlet water quality of artificial lake treatment system

\begin{tabular}{lccccc}
\hline index & $\begin{array}{c}\mathrm{COD}_{\mathrm{cr}} / \\
\mathrm{mg} \cdot \mathrm{L}^{-1}\end{array}$ & $\begin{array}{c}\mathrm{BOD}_{5 /} \\
\mathrm{mg} \cdot \mathrm{L}^{-1}\end{array}$ & $\begin{array}{c}\mathrm{NH}_{3}-\mathrm{N} / \\
\mathrm{mg} \cdot \mathrm{L}^{-1}\end{array}$ & $\begin{array}{c}\mathrm{TP} / \\
\mathrm{mg} \cdot \mathrm{L}^{-1}\end{array}$ & $\begin{array}{r}\mathrm{DO} / \\
\mathrm{mg} \cdot \mathrm{L}^{-1}\end{array}$ \\
\hline Inlet water & 30 & 6 & 1.5 & 0.3 & 3 \\
Outlet water & 20 & 4 & 1.0 & 0.2 & 5 \\
\hline
\end{tabular}

\subsection{Process flow}

Ecological purification technology mainly adopts artificial wetlands, ecological floating islands, and aquatic plant cultivation methods, and uses the soilmicrobe-plant ecosystem to effectively remove organic matter, nitrogen, phosphorus and other pollutants in water bodies. Comprehensive consideration of water purification, landscape improvement and climate adaptability of plants, we try to use local species with good purification effect, and pay attention to the spatial layout and matching of plants in the water body.

The artificial wetland purification mainly uses the physical, chemical, and biological triple synergy of soil, artificial media, plants, and microorganisms to achieve advanced purification and treatment of sewage through filtration, adsorption, co-precipitation, ion exchange, plant absorption, and microbial degradation ${ }^{[8-10]}$. According to the characteristics of the outlet water (tailwater) quality of the sewage plant, facultative and aerobic zones were set up in the water purification process of the wetland project to complete the conversion and removal of organic matter. The flow field was optimized to make the pollutants flow and purification mutually combined, maintain the ecological, natural, landscape and certain economical nature of the ecological engineering.

The study of sewage purification in constructed wetlands began in the late 1970s ${ }^{[11]}$. Germany uses horizontal and vertical flow wetland reed bed systems to treat nutrients ( $\mathrm{N}, \mathrm{P}$, etc.) in eutrophic water, and compares them. The results show that more than $90 \%$ of organic pollution and $\mathrm{N}, \mathrm{P}$ pollution are removed ${ }^{[12]}$. The average removal rate of $\mathrm{TN}$ in the Canadian subsurface reed wetland system during plant growth season was $60 \%$, TKN was $53 \%$, TP was $73 \%$, and average phosphate removal rate was $94 \%{ }^{[13]}$. The British reed bed vertical flow pilot system is used to treat high ammonia nitrogen sewage with an average removal rate of $93.4 \%{ }^{[14]}$.

The ecological floating bed or ecological floating island is based on aquatic plants and uses the principle of no soil cultivation technology to artificially build aquatic plant systems, degrade pollutants in water bodies and achieve water purification. Yang Jian ${ }^{[15]}$ showed that the biological floating island was selected as the degraded plant. After the operation was stable, the removal rate of CODcr, NH3-N, total phosphorus and turbidity could reach $60 \%, 64 \%, 43 \%$ and $83 \%$.

Generally, aquatic plants are divided into emergent plants, submerged plants, floating plants and floatingleaf plants. Aquatic plants such as water hyacinth, cattail, water celery, giant salamander, water onion and valerian have obvious purification effects on river black odor ${ }^{[16]}$.

\subsubsection{Process flow diagram}

Considering the treatment effect, landscape concept, project investment and operating costs, according to the analysis of the design inflow and outflow water quality, the main objectives include the removal of characteristic pollutants and the enhancement of dissolved oxygen in the water body. The block diagram of the design process flow is shown in Figure 1.

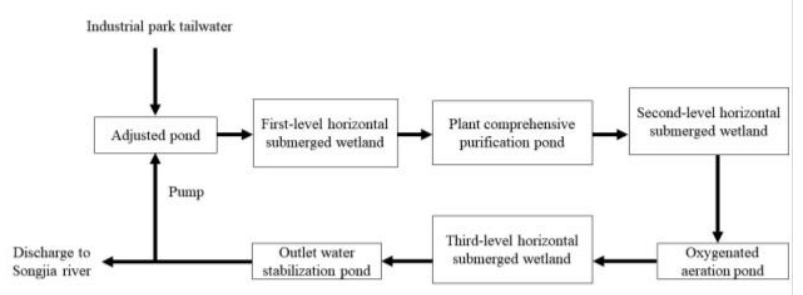

Figure 1 Process flow diagram

\subsection{Process description}

The main form of the water inlet adjustment pond is the horizontal surface flow artificial wetland. The tailwater discharged from the sewage plant in the industrial park first enters the pond to adjust the water quality and quantity. At the same time, the water quality is initially purified by gravel and shallow water plants. The outlet water of the adjusted pond is introduced into the first- 
level horizontal submerged wetland by collecting water pipeline, and the COD, ammonia nitrogen, total phosphorus and other substances in some water bodies are removed through the anaerobic reaction of microorganisms in the wetland; the outlet water from the first-level horizontal submerged wetland enters the plant comprehensive purification pond, and through a large number of growing and harvesting root-developed plants, nitrogen and phosphorus in most water bodies are transferred out of the water bodies. Due to the comprehensive action of plants, the types of microorganisms in the water body will increase in part. In this case, the outlet water of the plant comprehensive purification pond will be connected to the second-level submerged wetland, and the microorganisms will grow a lot in the gravel of the submerged wetland to further remove the pollutants in the water body. The outlet water from the second-level wetland flows into the oxygenated aeration pond by itself, and the dissolved oxygen in the water body is greatly increased under the action of the aquatic fountain aerator, which increases the activity of the water body and the diversity of the ecosystem, and the outlet water enters the third-level wetland. The thirdlevel wetland mainly processes the aerobic reaction. The reacted water is discharged into the outlet water stabilization pond. In this stage, the outlet water has reached the Class III water quality standard. The stabilization pond is mainly used to improve the buffering capacity of the whole river, and replenish water for the front channel through the pump, which can improve the overall velocity of the ecological lake body, and meet the demand of the ecological velocity. The remaining water is discharged through the landscape steel dam.

\section{Main processing unit}

\subsection{Adjusted pond}

The design of the water inlet water adjusted pond is a horizontal surface flow artificial wetland. The overall area is a gentle slope area. The main plants are emergent aquatic plants. These plants are arranged in layers. The reeds are planted at the high level, the white lotus and cattails are planted at the middle layer, and the lotus plants are planted at the bottom. The design parameters are as follows: the pond area is about $1800 \mathrm{~m}^{2}$; the depth of the water body is $0 \sim 1.5 \mathrm{~m}$; the water retaining time is $1 \mathrm{~d}$; the supporting water collection pipes are used to stably collect the water body in the area; a dam was built at the junction of the north water body and plant comprehensive purification pond.

\subsection{Horizontal submerged artificial wetland}

The horizontal submerged artificial wetland is located underground, which includes a cover layer, a filler layer and an impervious layer from top to bottom. The inlet water is collected and connected by the front-end collection pipe, and the outlet water is collected and discharged through the outlet channel. The design parameters are as follows: total area is about $4000 \mathrm{~m}^{2}$; the water retaining time is $1.1 \mathrm{~d}$; the COD load is $9.3 \mathrm{~g} /\left(\mathrm{m}^{2} \cdot \mathrm{d}\right)$; the hydraulic gradient is $0.5 \%$; the porosity is $40 \%$; the shape of pond is adjusted appropriately in combination with landscape design.
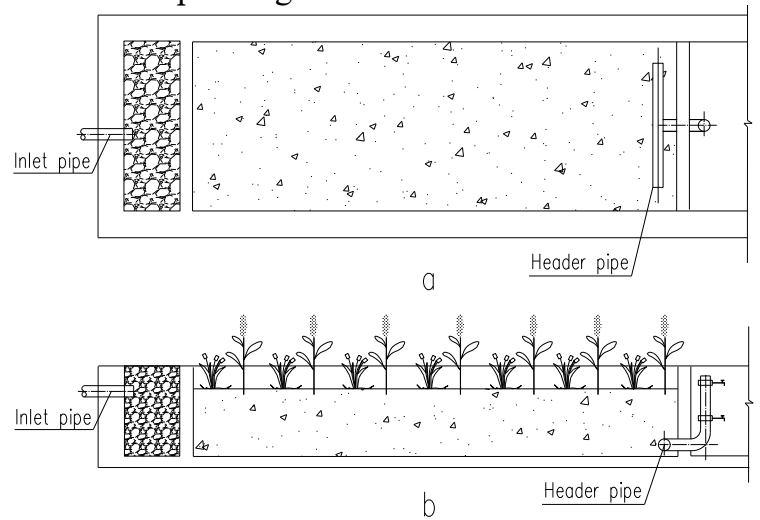

Figure 2 Structural diagram of horizontal submerged artificial wetland

\subsection{Plant comprehensive purification pond}

Through the setting of gentle slopes, shallow waters, transitions, and deep waters in the area, comprehensive plant purification ponds realize the diversity of ecosystems and achieve comprehensive purification of water bodies. The design parameters are as follows: the total area is about $7500 \mathrm{~m}^{2}$, of which $1500 \mathrm{~m}^{2}$ is gentle slope, $3000 \mathrm{~m}^{2}$ is shallow water area, $2000 \mathrm{~m}^{2}$ is transition zone, and $1000 \mathrm{~m}^{2}$ is deep water area; the water retaining time is $8 \mathrm{~d}$. The water depth: $0 \sim 1.0 \mathrm{~m}$ in gentle slope, $1 \sim 1.5 \mathrm{~m}$ in shallow water area, $1.5 \sim 2.0 \mathrm{~m}$ in transition zone, $2.0 \sim 2.5 \mathrm{~m}$ in deep water area;

The gentle slope area is mainly planted with emergent aquatic plants, the plants are arranged in layers, the reeds are planted in the upper layer, the white stalks and cattails are planted in the middle layer, and the lotus is planted in the bottom layer. The planting trough controls the growth range. Floating leaf plants are arranged in the depths of the lake bay and close to the water environment; submerged plants are properly combined to form a summer green and winter green submerged flora to keep the lake evergreen and floating. Leaf plants are arranged on the inner edge of submerged plants; combined ecological floating beds are arranged in the transition zone and deep water area, which mainly cultivated ornamental flower varieties, canna, parasol grass, etc. The planting form is adjusted in accordance with the landscape design. A water collecting pipe is equipped to stably collect the water body in the area. A dam is built at the junction of the east side of the water body and the oxygenation regulating pond.

\subsection{Oxygenated aeration pond}

The main role of oxygenated aeration pond is to aerate aquatic body with a large amount of oxygen through floating fountain aerator, improve the ecological activity of the water body, improve the viability of the entire ecosystem through the placement of aquatic animals, and 
complete the biological chain of the component. The design parameters are as follows: The total area is about $4000 \mathrm{~m}^{2}$, including $500 \mathrm{~m}^{2}$ in gentle slope area, $2000 \mathrm{~m}^{2}$ in shallow water area, $1000 \mathrm{~m}^{2}$ in transition zone, $500 \mathrm{~m}^{2}$ in deep water area; the water retaining time is $4.5 \mathrm{~d}$; the depth of water bodies are $0 \sim 1.5 \mathrm{~m}$ in gentle slope area, $1 \sim 1.5 \mathrm{~m}$ in shallow water area, $1.5 \sim 2.0 \mathrm{~m}$ in transition zone, and $2.0 \sim 2.5 \mathrm{~m}$ in deep water area.

Floating water aeration fountain: its oxygenation capacity is $0.35 \mathrm{~kg} \mathrm{O} \mathrm{O}_{2}$ per hour, power is $0.75 \mathrm{kw}$, and supporting with solar power system, and automatic control system. It can automatically start and stop according to the measured DO value.

Aquatic animal releasing: Based on the lakes with similar conditions and relatively reasonable fish structures in the same region, and appropriate adjustments were made. First, a small amount of filterfeeding fish was put in, while carnivorous fish communities were constructed to regulate the number of filter-feeding fish and protect zooplankton; secondly, the transparency of the water body and the resuspension of the substrate were control to help submerged plants compete with algae in the absorption of nutrients. The amount of omnivorous fish, herbivorous fish, and benthic feeding fish was strictly controlled. According to relevant experience, the recommended stocking ratio is $40 \% \sim 50 \%$ of carnivorous fish, $10 \% \sim 20 \%$ of filter-eating fish, $10 \% \sim 20 \%$ of omnivorous fish, less than $10 \%$ of benthic fish, and less than $6 \%$ of herbivorous fish. The total fish amount of this project were about 2,000. It should be carried out in batches, and from less to more.

\subsection{Outlet water stabilization pond}

The design form of outlet water stabilization pond is horizontal surface flow artificial wetland. The overall area is a gentle slope area, where mainly planted emergent aquatic plants. These plants were arranged in layers. Reeds were planted at the high level, civet white and cattails were planted at the middle layer, and lotus plants were planted at the bottom. The design parameters are as follows: the pond area is about $4000 \mathrm{~m}^{2}$; the depth of the water body: $0 \sim 1.5 \mathrm{~m}$; the water retaining time is $3 \mathrm{~d}$. Set a set of return flow system, supporting with two axial flow pumps, $\mathrm{Q}=1000 \mathrm{~m}^{3} / \mathrm{h}, \mathrm{H}=2 \mathrm{~m}, \mathrm{~N}=15 \mathrm{kw} / \mathrm{set}$; return pipeline was set, with pipe diameter $\varphi 350$, about $100 \mathrm{~m}$ length; supporting control system was set, which can realize automatic control. A dam was built at the junction of the north side of the water body and the aeration regulating pond.

\section{Running result}

\subsection{The ecological lake landscape effect map is shown in Figure 3.}

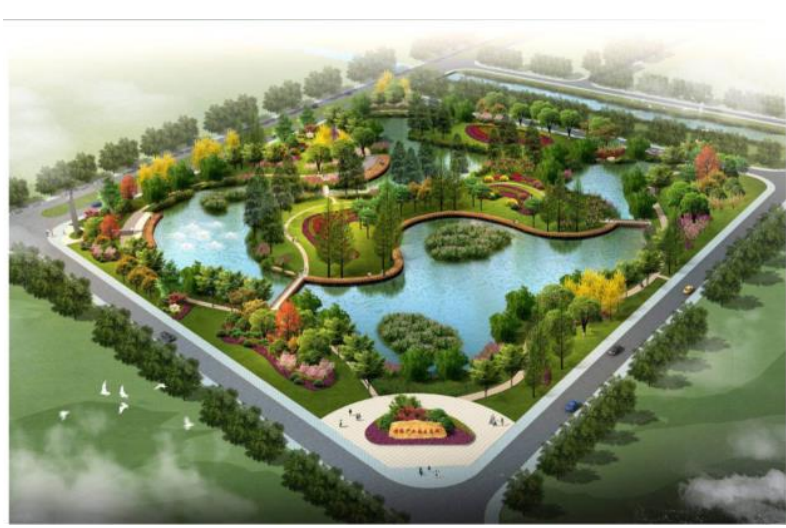

Figure 3 Aerial view of artificial ecological lake

\subsection{Ecological Lake Water Quality}

The project was completed in August 2019. The first month inlet water were tap water and some sewage treatment plant tailwater, and the second month inlet the sewage plant tailwater. After continuous operation for 3 months, the outlet water quality was tested, and water samples were collected every 7 days. The outlet water quality is shown in Table 2.

Table 2 Water quality of artificial ecological lake

\begin{tabular}{|c|c|c|c|c|c|}
\hline $\ln$ & $\begin{array}{l}\mathrm{COD}_{\mathrm{cr}} / \\
\mathrm{mg} \cdot \mathrm{L}^{-1}\end{array}$ & $\begin{array}{l}\mathrm{BOD}_{5 /} \\
\mathrm{mg} \cdot \mathrm{L}^{-1}\end{array}$ & $\begin{array}{c}\mathrm{NH}_{3}-\mathrm{N} / \\
\mathrm{mg} \cdot \mathrm{L}^{-1}\end{array}$ & $\begin{array}{c}\mathrm{TP} / \\
\mathrm{mg} \cdot \mathrm{L}^{-1}\end{array}$ & $\begin{array}{l}\mathrm{DO} / \\
\mathrm{mg} \cdot \mathrm{L}^{-1}\end{array}$ \\
\hline
\end{tabular}

\begin{tabular}{lllll}
\hline Concentration15.2-19.6 & $3.6-3.9$ & $0.88-0.93$ & $0.13-0.19$ & $5.5-7.1$
\end{tabular}

It can be seen from the test results of effluent water quality that the main pollutants in the tailwater of the sewage plant were degraded obviously by the artificial ecological lake, and the effluent water quality reached the Class III water standard of the Surface Water Environmental Quality Standard (GB3838-2002), effectively reducing the discharge of pollutants into the river

\section{Conclusion}

This project uses artificial ecological lake to treat the tailwater of the sewage treatment plant, which can not only reduce pollutants and improve water quality, but also beautify the environment. It has the advantages of low investment and operation cost and good purification effect. The combination of the landscaping value of wetland plants and the art of gardening landscape has added an artificial ecological wetland landscape to the industrial park, which has good social and environmental benefits.

\section{References}

1. ZHANG Yun, CAI Binbin. Application of ecological wetland technology in in-depth treatment 
of tail water from municipal sewage plant [J]. Yangtze R iver. 2017,48(10):30-32.

2. Angéline B, Pedro A I, Renato A Q . A theoretical estimation of the concentration of steroid estrogens in effluents released from municipal sewage treatment plants into aquatic ecosystems of central-southern Chile [J]. Science of the Total Environmental, 2009, 407 (17) : 4965.

3. AN Hongmei,WU Libo,YUE Shangchao. Experimental study on removal of ammonia nitrogen in secondary effluent by clinoptilolite [J].Chinese Journal of Environmental Engineering, 2010, 4(5): 1111.

4. Han $R$ uirui, Yuan Linjiang, Kong Haixia . Purification of secondary effluent from WWTP by integrated vertical-flow constructed wetland [J]. China Water \& Wastewater, 2009, 25 (21) : 50-52 (in Chinese)

5. Woodward R T, Wui Y. The economic value of wetland services: Ameta- analysis[J].Ecological Economics, 2001,37 (2) : 257-270.

6. Zdraga. The effect of environmental conditions on the ability of a constructed wetland to disinfect municipal wastewaters [J]. Environmental Management, 2002, 29 (4) : 510-515.

7. WU Shubiao,DONG Renjie. Constructed Wetlands for Water Pollution Control: An Ecological Theory and Technology [M]. China : China Forestry Publishing House, 2016:4-5.

8. WANG Shihe. Theory and technology of sewage treatment in Constructed Wetland [M]. Beijing: Science Press ( in Chinese), 2007.

9. WU Xiaolei . Mechanism of Wastewater Treatment in Constructed Wetlands [J]. Environmental Science 1995,16( 3) : 83-86 .

10. LIANG Wei, HU Hongying. Biological function of constructed wetland in sewage purification [J]. China Water \& Wastewater, 2003,19(10):82-85.

11. Verhoeven J T A, Meuleman A F M. Wetlands for waste water treatment: opportunities and limitations [J].Ecological Engineering, 1999, 12:5-12.

12. Volker L, Elke E, Martina L, et al. Nutrient removal efficiency and resource economics ofvertical flow and horizontal flow constructed wetlands [J].Ecollogical Engineering,2001,18:157-171.

13. Garba L, Jacques B, Linda D, et al. Nitrogen and phosphorus removal in a subsurface-flow reed bed[J].Water Quality Research Journal of Canada, 1998,33(2):319-329.

14. Michael M, Robert H. The design and performance of a vertical flow reed bed for the treatment of high ammonia low suspended solids organic effluents[J].WatSci Tech.,1997,35(5):197-204.

15. Yang Jian. Biological floating island + biological column combination module for urban black odor water treatment research [J]. Environmental Science and Development, 2018 (2): 96-97.

16. Dong Zheren, Liu Qian, Zeng Xianghui. Bioecological restoration technology of polluted water bodies[J].Water Resources and Hydropower Engineering,2002,33(2):1-5. 